\section{CIUDAD DE MÉXICO, QUINCE AÑOS DE DESARROLLO URBANO INTENSIVO: LA GENTRIFICACIÓN PERCIBIDA*}

Víctor Delgadillo**

\section{Resumen}

Quince años de desarrollo urbano intensivo han producido un paisaje urbano cada vez más exclusivo y excluyente en selectas áreas centrales de la Ciudad de México. Las zonas céntricas que de manera privilegiada han sido revalorizadas por las inversiones públicas y privadas son áreas fabriles obsoletas, baldíos urbanos y barrios patrimonializados, de clase media y popular, relativamente despoblados, bien comunicados y declarados "decadentes" por las autoridades. Este artículo explora la percepción de la población residente en diez barrios centrales, objeto de distintos tipos de presiones inmobiliarias, sobre la transformación y gentrificación de sus barrios, a partir de una

\section{MEXICO CITY, 15 YEARS OF INTENSIVE URBAN DEVELOPMENT: PERCEIVED GENTRIFICATION*}

Víctor Delgadillo**

\section{Abstract}

Fifteen years of intensive urban development have given rise to exclusive and exclusionary urban landscapes in the central areas of Mexico City. Obsolete industrial districts, derelict urban land and relatively abandoned and well-connected middle and lower-class neighborhoods -which have been regarded by authorities as "run-down areas" - are some of the areas that have benefited the most from public and private investment. This paper explores the perception of local residents, caputured in an extensive survey conducted with more than 3,000 inhabitants in August 2014 from 10 central areas, about the transformation and gentrification of their neighbourhoods -which 
mega-encuesta aplicada a tres mil residentes en agosto de 2014. El artículo: a) presenta los referentes teóricos y la estrategia metodológica desarrollada en esta investigación; b) revisa las políticas de desarrollo urbano intensivo acompañadas del incremento de inversiones inmobiliarias trasnacionales y megaproyectos públicos; y, c) analiza la percepción de los residentes sobre la transformación y gentrificación de sus barrios de cara a década y media de desarrollo urbano "sustentable", que han contribuido a reforzar las históricas desigualdades socio-espaciales en las áreas urbanas centrales, $\mathrm{y}$ en selectos barrios centrales han transformado sustancialmente el paisaje urbano y social.

\section{PALABRAS CLAVE: DESARROLLO URBANO INTENSIVO; DENSIFICACIÓN; GENTRIFICACIÓN; CIUDAD DE MÉXICO.}

\author{
Recibido: 09-03-2016
}

Aceptado: 30-09-2016

* Este artículo se desarrolló a partir del Grupo de Investigación “Hábitat y centralidad. Dinámicas urbanas, conflictividad socioespacial y políticas públicas en los procesos de transformación de los espacios de centralidad urbana e histórica en la ciudad de México", financiado por el CONACYT - investigación científica básica 168252, que está integrado por investigadores de tres universidades públicas con intereses diferentes, pero convergentes en esos territorios.

* México. Profesor investigador Universidad Autónoma de la Ciudad de México. Correo electrónico:victor_delgadill@hotmail.com have been subject to real estate pressure. This research: a) describes the theoretical references and methodological strategies developed throughout the research, b) analyzes the intensive urban development and the increase in investment, presence of international real estate firms and public megaprojects; and c) studies the perception of dwellers about the transformation and gentrification of neighborhoods after a decade and a half of "sustainable" urban development, which has led to the reinforcement of historical sociospatial inequality in central urban areas and the transformation of the urban and social landscape as the result of the emergence of exclusive central neighborhoods.

\section{KEYWORDS: INTENSIVE URBAN DEVELOPMENT; DENSIFICATION; GENTRIFICATION; MEXICO CITY}

Received: 09-03-2016

Accepted: 30-09-2016

* This paper was developed by the "Habitat and Centrality. Urban Dynamics, Socio-Spatial Conflicts and Public Policies within the Context of the Transformation Process of Urban and Historic Central Spaces in Mexico City" Research Project, funded by CONACYT -basic scientific research 168252, which is composed of researchers from three public universities that have different interests but share the same territory.

* Mexico. Professor and researcher, Universidad Autónoma de la Ciudad de México. Email: victor_delgadill@hotmail.com. 


\section{Introducción}

Quince años de ininterrumpidas políticas públicas de desarrollo urbano intensivo, con distintos nombres y énfasis, han producido un nuevo paisaje urbano, caro, exclusivo y excluyente para la mayoría de la población en selectas áreas centrales de la Ciudad de México. La preocupación por el cambio climático y el medio ambiente ha sido la base para la promoción pública de negocios inmobiliarios, mientras que la ciudad compacta se ha convertido en un lujo al que sólo las clases medias y altas pueden acceder. Las áreas urbanas que selectivamente se han revalorizado o se pretenden transformar son zonas fabriles obsoletas, baldíos intraurbanos, barrios de clase media y colonias ${ }^{1}$ populares patrimonializadas y muy bien comunicadas, que han sido declaradas "decadentes".

Por ser zonas relativamente despobladas o aparentemente deshabitadas no hay evidencias de grandes sino de puntuales desalojos y desplazamientos de población residente, invisibilizados por la prensa y desapercibidos por la academia. Por ello, algunos funcionarios públicos y académicos afirman que en la Ciudad de México no hay procesos de gentrificación o que la gentrificación no desplaza población. Otra característica que influye en los actuales procesos de transformación en la Ciudad de México, es que varios de los territorios revalorizados por el capital y la política pública son áreas patrimonializadas por sus atributos físicos e históricos. Aquí, la legislación que protege el patrimonio limita la captura de la renta potencial, pues impide la transformación radical de los edificios históricos y la construcción de mayores alturas y superficies. En algunos casos los inversionistas recurren a la destrucción clandestina del patrimonio edilicio para construir edificios de mayores alturas; a la preservación de la fachada o la primera crujía, para construir más pisos atrás del predio o sobre el edificio.

En este artículo, revisamos brevemente las teorías de la gentrificación, tanto las que se basan en la producción como las que se anclan en el consumo, como marco para explorar la percepción de los residentes sobre la gentrificación de sus barrios en la Ciudad de México. En este mismo apartado, explicamos la metodología de la investigación, cuya parte central consistió en la aplicación de tres mil encuestas a residentes de diez barrios centrales.

1 En México, el término de colonia y barrio se usan indistintamente. La colonia, de origen decimonónico, es un asentamiento humano que se crea en territorios que no eran parte de la ciudad. El barrio, de origen colonial, es una subdivisión de la ciudad. La expansión urbana absorbió a las colonias que una vez estuvieron distantes de la ciudad. 
Enseguida, se presenta un panorama general de quince años de políticas de desarrollo urbano intensivo, que recientemente se acompañan del incremento de inversiones inmobiliarias trasnacionales, así como de megaproyectos públicos que prácticamente pretenden quitar los barrios a su población en aras de creativos y rentables negocios inmobiliarios. El tercer apartado analiza los resultados de la mega-encuesta en torno a la percepción de la población residente sobre la transformación y/o gentrificación de sus barrios. En las conclusiones retomamos la relación entre la política de desarrollo urbano intensivo con la percepción diferenciada de la población sobre la transformación de diez barrios centrales, que muestra que una misma política general impacta de manera diferente y simultánea las áreas centrales.

\section{Gentrificación, producción y consumo}

La transformación de selectos barrios obreros o populares decadentes y áreas urbanas abandonadas en territorios de consumo para clases medias, a través de fuertes inversiones públicas y grandes negocios privados, ha sido estudiada desde la perspectiva de los consumidores y de los productores. Sin embargo, no se trata de una dicotomía ni de perspectivas teóricas excluyentes. Actualmente, los procesos de gentrificación se explican como un fenómeno que abarca la oferta y la demanda, las dimensiones de la producción y del consumo, y las esferas de la economía y la cultura. De la misma forma que los consumidores (co)producen la gentrificación y el espacio urbano; los productores también consumen. Cada investigador, de acuerdo a su postura teórica, formación académica y metodologías de investigación enfatiza en los aspectos que considera relevantes.

Quienes ponen énfasis en el consumo han explicado los procesos de gentrificación en función de los cambios en la base económica de las ciudades (de la industria a los servicios), la expansión de las clases medias, el papel de la economía del conocimiento y las "clases creativas", y el incremento de las industrias culturales. Estas investigaciones también destacan la emancipación de la mujer, las luchas de las comunidades lésbico-gay, y la revalorización del patrimonio histórico edificado². Desde la perspectiva de la producción, los énfasis de las investigaciones se han puesto en los procesos de desinversión reinversión, la captura de las brechas de renta, las inversiones inmobiliarias locales y trasnacionales, las políticas urbanas y las modificaciones a las regulaciones urbanas que permiten usos lucrativos y mayores índices de construcción ${ }^{3}$.

2 Lees, Slater y Wyly, 2008.

3 Ibíd. 
Según esta versión, los verdaderos gentrificadores no son los consumidores individuales, sino los actores privados y públicos que tienen capacidad para cambiar el destino de barrios y centros urbanos. Aquí, más que la población, quien retorna al centro es el capital ${ }^{4}$.

En América Latina los estudios sobre los procesos de gentrificación son relativamente recientes pero muy diversos ${ }^{5}$. Varias investigaciones parten de una definición "clásica" que indica que la gentrificación se caracteriza por su contenido de clase y el despojo de sus barrios a la población de menores ingresos, para destinarlos a los negocios inmobiliarios y al consumo de población de mayores ingresos ${ }^{6}$. Asimismo, dos de las principales características de la gentrificación en las ciudades latinoamericanas son: 1) El papel del Estado que, a través de políticas urbanas neoliberales y pro empresariales ${ }^{7}$, promueve los negocios privados, legitimados bajo el discurso del desarrollo urbano sustentable; y 2) El papel protagónico de los centros y barrios históricos, en términos de las políticas que revalorizan el patrimonio urbano en sus múltiples dimensiones (materiales, simbólicas, económicas, culturales), excluyen ciertas prácticas

\footnotetext{
4 Smith, 1979.

5 Delgadillo, Díaz y Salinas, 2015.

6 Casgraín y Janoschka, 2013.

7 López Morales, 2013.
}

populares (comercio ambulante, indigencia) y criminalizan la pobreza ${ }^{8}$.

No hay aquí espacio sino para ejemplificar algunas de las múltiples aristas y énfasis en estos estudios: Rodríguez $z^{9}$ señala que tanto los ciclos políticos (con las orientaciones políticas de los distintos gobiernos que se suceden en el poder) como la capacidad de resistencia y oposición de los movimientos sociales, influyen en los procesos de gentrificación. Quiroz y Cadena ${ }^{10}$ consideran que en la Ciudad de México coexisten procesos de gentrificación planificada y de gentrificación espontánea: la primera se desarrolla a partir de la colaboración de gobernantes e inversionistas, y la segunda se produce por la suma de iniciativas individuales de consumidores que deciden habitar y consumir en ciertos barrios no mejorados aún por las políticas públicas. Otros colegas ${ }^{11}$ dan cuenta de la coexistencia de nuevos consumidores y residentes de mayores ingresos con residentes de menores ingresos, y de lofts y tugurios, en barrios y centros históricos revalorizados.

Para quien escribe, la gentrificación es una herramienta conceptual clave para estudiar la interconexión y transversalidad de una gran diversidad de aspectos y procesos en la ciudad: las políticas

8 Delgadillo, 2014

9 Rodríguez, 2015.

10 Quiroz y Cadena, 2015

11 Delgadillo, 2014; y Hiernaux y González, 2014. 
públicas, la gestión urbana, la movilidad residencial, la segregación funcional y social de y en la ciudad, la postura política de funcionarios públicos y académicos, la globalización de la economía capitalista neoliberal, el marketing de la ciudad, etcétera. Las metodologías utilizadas por los investigadores en los estudios sobre la gentrificación están estrechamente vinculadas con los enfoques y las escalas y dimensiones exploradas. Algunos autores han puesto un gran énfasis en la escala individual y micro (entrevistas, etnografías, historias de vida), mientras que otros autores analizan la dimensión urbana y económica (estadísticas de población, vivienda, mercado inmobiliario), por ello, unos presentan la gentrificación como un fenómeno local y otros como un fenómeno en escala metropolitana. En la región reconocemos que ha habido una tendencia al estudio de caso $^{12}$ y que son escasos los análisis cuantitativos para evidenciar el desplazamiento social. En este artículo, nos queremos sumar a los estudios sobre la gentrificación a partir de la percepción que tres mil residentes tienen sobre sus barrios centrales habitados.

\section{Metodología}

El grupo de investigación "Hábitat y centralidad", del que se deriva esta investigación y artículo, aplicó una Encuesta Probabilística, cara a cara a residentes de 3.000 viviendas en diez "áreas testigo" (secciones de barrios) seleccionadas por nosotros en función del conocimiento previo de esos territorios, la presencia de conflictos sociales derivados de inversiones privadas y públicas, y por representar un tipo de poblamiento de las áreas centrales de la Ciudad de México en función de ciertos criterios: origen del barrio, perfil socioeconómico de su población, densidad habitacional, patrimonio urbano, uso no habitacional y funciones de centralidad.

La encuesta, amplia y compleja, tiene 134 preguntas centrales y secundarias (25 son abiertas) y se integra por bloques relativos a: composición del hogar, características de la vivienda, tiempo de residencia (en la ciudad, el barrio y la vivienda), (des)ventajas de habitar los barrios centrales, medios de transporte usados, transformación del barrio, patrimonio urbano, participación ciudadana, y gobernanza y corrupción. En este artículo únicamente tomamos en cuenta el grupo de preguntas que se refieren a la percepción de los residentes sobre la transformación de sus barrios.

12 Delgadillo, Díaz y Salinas, 2015. 


\section{MAPA 1. DIEZ BARRIOS CENTRALES EN LA CIUDAD DE MÉXICO}

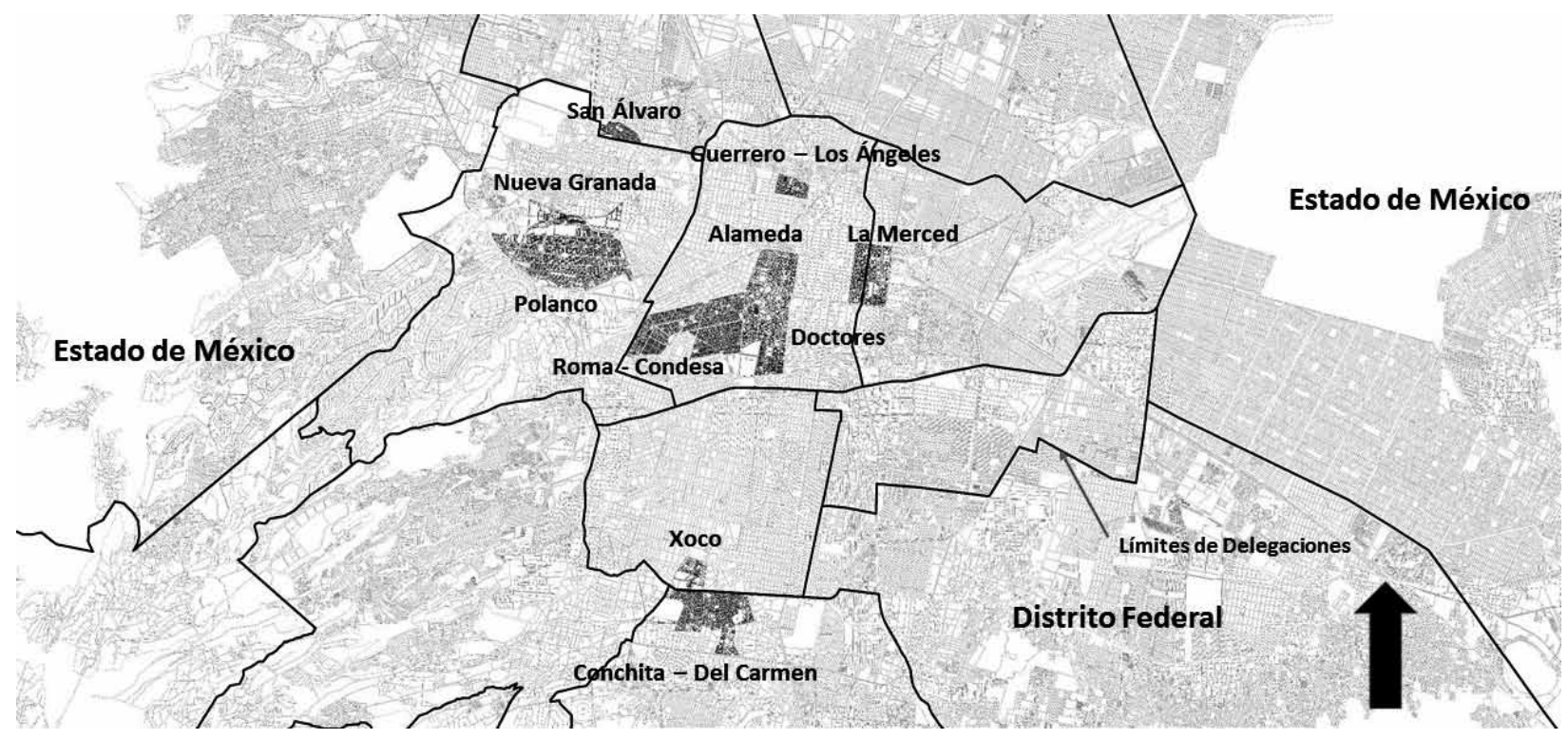

Fuente: Elaboración propia

\section{Las 10 áreas testigo}

Las diez áreas urbanas centrales (mapa 1) definidas para la aplicación de la encuesta son muy diferentes y no se revalorizan de la misma forma.

Cada polígono presenta diferentes tipos de hábitat, centralidad, relaciones, tensiones y conflictos entre los distintos actores sociales, económicos y políticos. Por cuestión de espacio sintetizamos las principales características en la tabla 1 , mientras que en las imágenes ilustramos los tipos de poblamiento y sus problemáticas. 


\section{FIGURA 1. CONJUNTO REQUENA, REHABILITADO DESPUÉS DE LOS SISMOS DE 1985 Y, AL FONDO CONJUNTO SOLDOMINIOS, CONSTRUIDO EN SUSTITUCIÓN DE VECINDADES (CONVENTILLOS).}

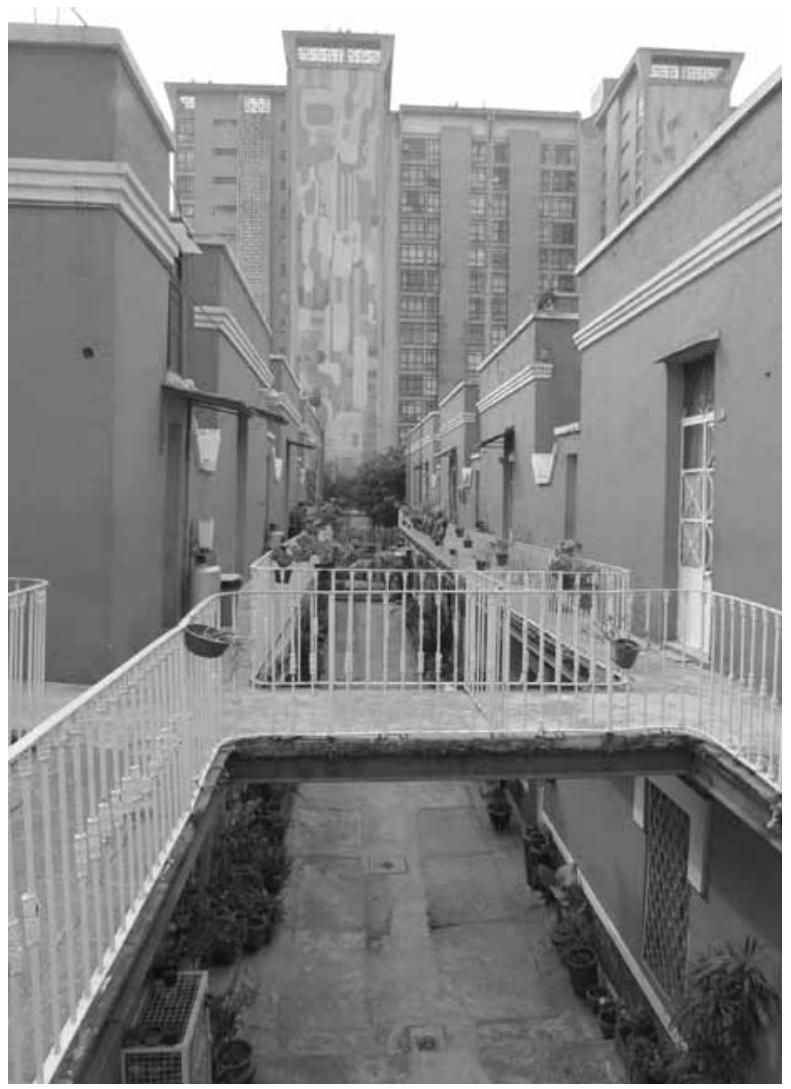

Foto: Víctor Delgadillo.

\section{FIGURA 2. CAMPAMENTO DE DAMNIFICADOS PROVENIENTE DE LOS SISMOS DE 1985.}

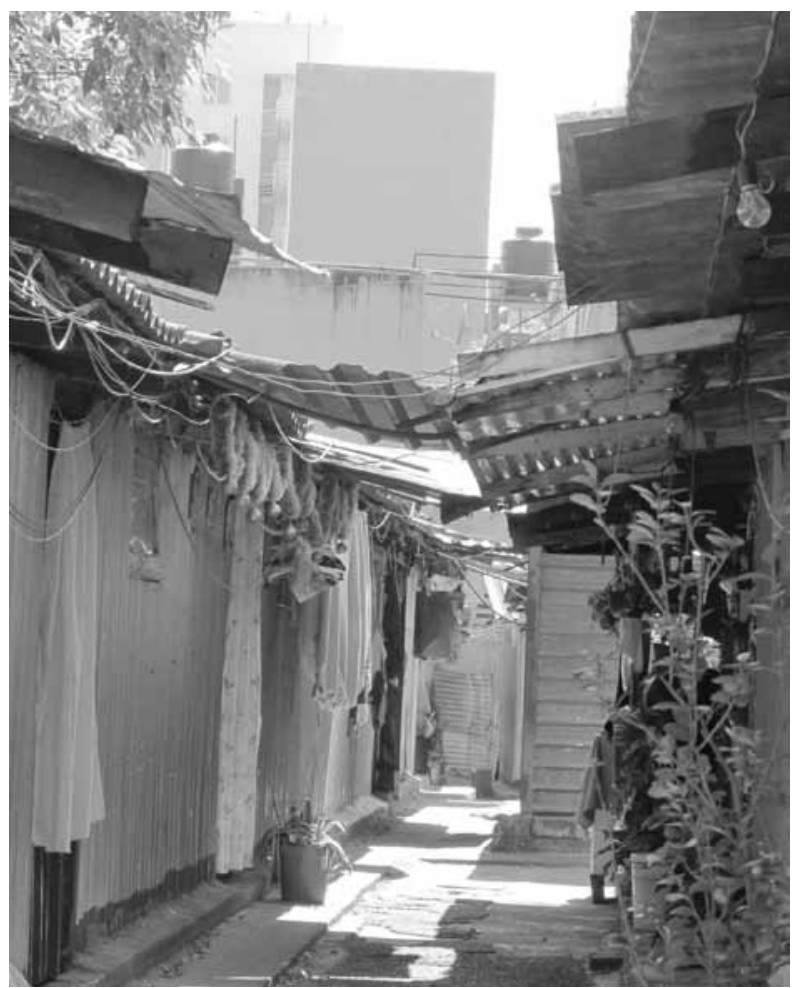

El Instituto de Vivienda del Gobierno del Distrito Federal pretendió (sin éxito) reubicar a la población que ocupa el campamento en otro lugar, para destinar ese terreno a la construcción de torres de departamentos para el mercado libre, en una operación financiera "sustentable".

Foto: Víctor Delgadillo. 
FIGURA 3. PLAZA DE “EL AGUILITA" QUE MUESTRA UN CAMPAMENTO TRANSITORIO DE DESALOJADOS DE UNA VECINDAD.

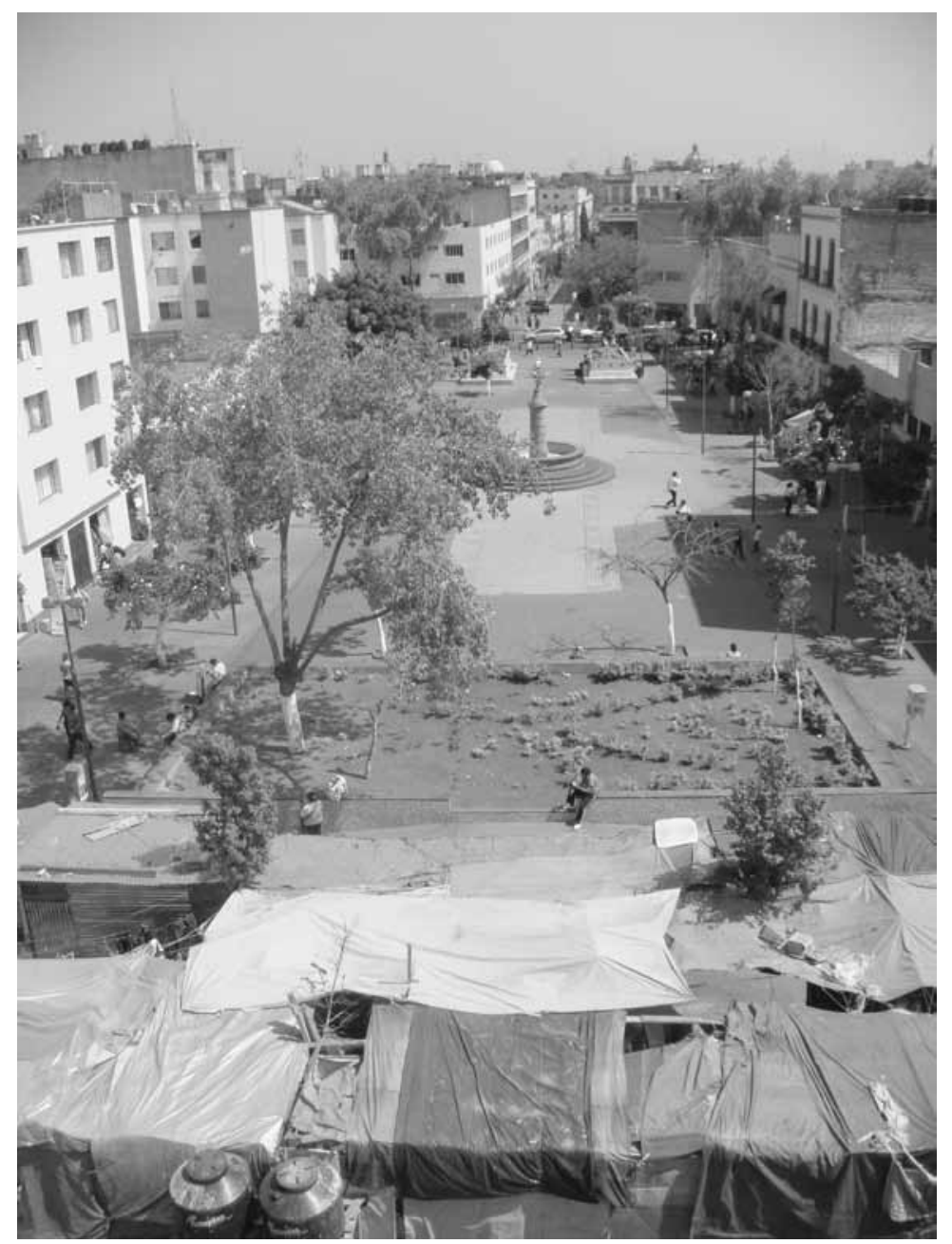

Foto: Víctor Delgadillo. 


\section{TABLA 1. PRINCIPALES CARACTERÍSTICAS DE DIEZ BARRIOS CENTRALES}

\begin{tabular}{|c|c|c|c|c|c|c|c|c|c|c|}
\hline Barrio & Alameda Sur & $\begin{array}{l}\text { Concepción } \\
\text { Del Carmen }\end{array}$ & Doctores & $\begin{array}{l}\text { Guerrero } \\
\text { Los } \\
\text { Ángeles }\end{array}$ & $\begin{array}{l}\text { Nueva } \\
\text { Granada }\end{array}$ & Polanco & $\begin{array}{l}\text { Roma } \\
\text { Condesa }\end{array}$ & San Álvaro & $\begin{array}{l}\text { Vieja } \\
\text { Merced }\end{array}$ & Xoco \\
\hline Delegación & Cuauhtémoc & Coyoacán & Cuauhtémoc & Cuauhtémoc & $\begin{array}{l}\text { Miguel } \\
\text { Hidalgo }\end{array}$ & $\begin{array}{l}\text { Miguel } \\
\text { Hidalgo }\end{array}$ & Cuauhtémoc & Azcapotzalco & $\begin{array}{l}\text { Cuauhtémoc } \\
\text { / Venustiano } \\
\text { Carranza }\end{array}$ & $\begin{array}{l}\text { Benito } \\
\text { Juárez }\end{array}$ \\
\hline $\begin{array}{l}\text { Estrato socio- } \\
\text { económico }\end{array}$ & Popular & Medio y alto & Popular & Popular & $\begin{array}{l}\text { Medio y alto. } \\
\text { Popular }\end{array}$ & Alto & Medio y alto & Popular & Popular & $\begin{array}{l}\text { Medioy } \\
\text { popular }\end{array}$ \\
\hline Antigüedad & Siglo XVII & $\begin{array}{l}\text { Concepción: } \\
\text { Siglo XVI. } \\
\text { Del Carmen: } \\
1890\end{array}$ & Siglo XVII & Siglo XIX & $\begin{array}{l}\text { Siglo XX } \\
\text { Fábricas } \\
\text { y barrios } \\
\text { obreros }\end{array}$ & Siglo XX & Siglo XX & Siglo $X X$ & Siglo XVI & Siglo XVI \\
\hline $\begin{array}{l}\text { Tipo de } \\
\text { centralidad }\end{array}$ & $\begin{array}{l}\text { Parque } \\
\text { Alameda, } \\
\text { museos }\end{array}$ & $\begin{array}{l}\text { Museos, } \\
\text { librerías, } \\
\text { cafés }\end{array}$ & $\begin{array}{l}\text { Tribunales } \\
\text { de Justicia y } \\
\text { hospitales }\end{array}$ & & $\begin{array}{l}\text { Centro corpo- } \\
\text { rativo (Carso, } \\
\text { Inbursa, } \\
\text { Telmex) }\end{array}$ & $\begin{array}{l}\text { Centro } \\
\text { gastronómi- } \\
\text { co, culturaly } \\
\text { bares }\end{array}$ & $\begin{array}{l}\text { Centro } \\
\text { gastronómi- } \\
\text { co, culturaly } \\
\text { bares }\end{array}$ & & $\begin{array}{l}\text { Patrimonio } \\
\text { edilicio y } \\
\text { mercados }\end{array}$ & $\begin{array}{l}\text { Cineteca, } \\
\text { Centro } \\
\text { comercial }\end{array}$ \\
\hline $\begin{array}{l}\text { Zona } \\
\text { patrimonial }\end{array}$ & $\begin{array}{l}\text { CH Períme- } \\
\text { tro B }\end{array}$ & $\mathrm{ACP}$ & & & & $\mathrm{ACP}$ & $\mathrm{ACP}$ & ACP & $\begin{array}{l}\text { CH Perímetro } \\
\text { AyB }\end{array}$ & $\begin{array}{l}\text { ACP } \\
\text { (recortada) }\end{array}$ \\
\hline Área (Has) & 12.13 & 24.27 & 23.94 & 39.82 & 15.79 & 35.54 & 31.86 & 38.00 & 14.17 & 62.03 \\
\hline Manzanas & 78 & 138 & 204 & 40 & 87 & 217 & 248 & 34 & 141 & 13 \\
\hline $\begin{array}{l}\text { Población } \\
\text { total }\end{array}$ & 13,620 & 11,961 & 42,036 & 11,333 & 9,912 & 30,900 & 36,223 & 6,743 & 24,736 & 4,002 \\
\hline $\begin{array}{l}\text { Mayores de } \\
18 \text { años }\end{array}$ & 10,065 & 9,171 & 30,901 & 8,142 & 7,582 & 19,446 & 28,445 & 5,026 & 16,382 & 2,825 \\
\hline $\begin{array}{l}\% \text { mayores de } \\
65 \text { años }\end{array}$ & 7.72 & 16.20 & 8.41 & 8.32 & 5.24 & 11.66 & 9.91 & 12.61 & 6.84 & 8.90 \\
\hline $\begin{array}{l}\text { Conjuntos } \\
\text { vivienda } \\
\text { social }\end{array}$ & 0 & 11 & 61 & 12 & 11 & 0 & 0 & 0 & 15 & 0 \\
\hline $\begin{array}{l}\text { Total de } \\
\text { viviendas }\end{array}$ & 6,352 & 4,578 & 16,339 & 3,337 & 3,817 & 14,839 & 14,531 & 2,412 & 7,897 & 1,377 \\
\hline $\begin{array}{l}\text { Viviendas } \\
\text { deshabitadas }\end{array}$ & 1,666 & 384 & 2,619 & 465 & 1,092 & 3,331 & 2,458 & 385 & 1,193 & 86 \\
\hline $\begin{array}{l}\text { Mega- } \\
\text { proyecto } \\
\text { y presión } \\
\text { inmobiliaria }\end{array}$ & $\begin{array}{l}\text { Edificios de } \\
\text { departamen- } \\
\text { tos Sur de la } \\
\text { Alameda }\end{array}$ & $\begin{array}{l}\text { Condominios } \\
\text { horizontales } \\
\text { y cambios } \\
\text { de uso del } \\
\text { suelo }\end{array}$ & $\begin{array}{l}\text { ZODES } \\
\text { Ciudad admi- } \\
\text { nistrativa }\end{array}$ & & $\begin{array}{l}\text { Torres de } \\
\text { oficinas y de- } \\
\text { partamentos }\end{array}$ & $\begin{array}{l}\text { Sustitución } \\
\text { edilicia (casas } \\
\text { por torres) }\end{array}$ & $\begin{array}{l}\text { Cambios de } \\
\text { uso del suelo. } \\
\text { Sustitución } \\
\text { edilicia (casas } \\
\text { por torres) }\end{array}$ & & $\begin{array}{l}\text { Rescate } \\
\text { integral de La } \\
\text { Merced }\end{array}$ & $\begin{array}{l}\text { Mitikah } \\
\text { Ciudad } \\
\text { progresiva }\end{array}$ \\
\hline
\end{tabular}

CH: Centro Histórico.

ACP: Área de Conservación Patrimonial.

Fuente: Elaboración propia. 


\section{Quince años de desarrollo urbano intensivo}

Al iniciar el siglo XXI, el área metropolitana de la Ciudad de México vivía una compleja problemática urbana que podría sintetizarse en dos grandes tendencias de desarrollo urbano: el despoblamiento y la terciarización de sus áreas urbanas centrales; y la expansión urbana (in)formal de las periferias. En esta metrópolis, históricamente la población se ha distribuido desigualmente en relación directa con los mercados de suelo y vivienda. Así, desde 1990 la menor cantidad de población del área metropolitana vive en el Distrito Federal (DF) o Ciudad de México, y la mayor parte radica en los vecinos municipios del Estado de México, algunos de ellos conurbados desde 1950. Además, la tercera parte de la población del DF reside en dos de las 16 Delegaciones en que administrativamente se divide la capital mexicana: Iztapalapa y Gustavo A. Madero, demarcaciones con muchas carencias urbanas y rezagos sociales.

A partir de 2000, en el marco de una política económica voraz de construcción de vivienda de dimensiones minúsculas, en escala nacional se inició una nueva fase de expansión urbana en periferias distantes de las ciudades. Esta urbanización formal se basó en el acceso a suelo rural barato; la descentralización de atribuciones a los municipios (que pueden hacer el plan de desarrollo urbano de su demarcación y emitir sus propias licencias de construcción); la privatización de la propiedad rural colectiva; la desregulación de las normas urbanas y de vivienda; y la mutación de los organismos públicos de vivienda, de constructores a financiadores. Este modelo habitacional confinó a la población de bajos ingresos a las periferias distantes, donde ellos pueden pagar una vivienda propia; generó una extensiva urbanización altamente segregada que obliga a sus residentes a realizar grandes traslados para acceder al trabajo, los servicios y equipamientos; mientras que la vivienda producida es de dimensiones mínimas y de pésima calidad. El Estado mexicano abdicó a su responsabilidad de controlar la calidad de la vivienda y de ordenar el territorio y el desarrollo urbano, y dejó estas tareas al sector privado.

A partir de ese mismo año 2000, el Gobierno del Distrito Federal (GDF) inició una política de desarrollo urbano intensivo que se propuso combatir el despilfarro de la ciudad construida (expresado en la pérdida de población y vivienda en áreas urbanas centrales) y la expansión urbana, y proteger las áreas de conservación ecológica. Esta política se impulsó a través de restricciones urbanísticas, programas habitacionales, la rehabilitación de un selecto patrimonio histórico y acciones en ciertos espacios públicos. Así, selectas áreas urbanas centrales han sido revalorizadas en términos simbólicos y materiales: se han elevado los precios del suelo y los costos de las viviendas. En este contexto, 
algunos barrios centrales rehabilitados se han posicionado como destacados lugares para el consumo de una población de mayores ingresos que los antiguos residentes.

\section{Políticas de desarrollo urbano intensivo}

Desde el año 2000 los sucesivos gobiernos del DF han puesto un especial énfasis en políticas de desarrollo urbano intensivo, para evitar la expansión urbana, proteger el medio ambiente, reducir el uso de transporte, etcétera. Bajo distintos eslóganes (Bando 2, Desarrollo urbano sustentable, Ciudad compacta) las políticas urbanas se han propuesto: repoblar el centro, "recuperar" el espacio público, redensificar las áreas con buena conexión de transporte y suficientes servicios; crear nuevas zonas de desarrollo económico y social; regenerar y reciclar corredores urbanos, centros de barrio y el patrimonio urbano ${ }^{13}$.

Curiosamente la Ciudad compacta desde 2014 también es el discurso del gobierno federal. Después de dos sexenios de una urbanización periférica colosal, que fue conducida por la política habitacional que buscaba combatir el déficit de vivienda y de patrimonio familiar (vivienda en régimen de

13 Jefatura de Gobierno, 2013; Secretaría de Desarrollo Urbano y Vivienda, 2013. propiedad privada), el gobierno federal ahora promueve el desarrollo urbano "compacto". Esto es expresado en el estudio México compacto ${ }^{14}$ y en el Plan Nacional de Desarrollo Urbano 2014-2018 15 que pretende: controlar la expansión territorial de las ciudades, a través de la promoción y el reemplazo de vivienda al interior de las urbes; utilizar el suelo intraurbano disponible y densificar los barrios.

Así, en la Ciudad de México en los últimos 15 años las políticas de desarrollo urbano intensivo, apoyadas por diversas políticas públicas y grandes proyectos urbanos, han tenido una continuidad bajo distintos nombres y diferentes énfasis secundarios. En la tabla 2 sintetizamos las principales políticas de desarrollo urbano intensivo desplegadas desde el año 2000.

El Bando (informativo) Dos fue una pragmática política restrictiva de desarrollo urbano que permitía la construcción de conjuntos de más de 35 viviendas en sólo cuatro Delegaciones que integran la "Ciudad central" (y la prohibía en el resto del DF), para repoblar una zona que entre 1970 y 2000 perdió 1.2 millones de residentes. Esta política se propuso además promover la construcción de vivienda para población "humilde", cosa que no se hizo sino de manera muy puntual en un suelo encarecido por esa misma política. Los

14 Senado de la República, Fundación IDEA y SIMO Consulting, 2014.

15 Secretaría de Desarrollo Agrario, Territorial y Urbano, 2014. 
desarrolladores inmobiliarios tuvieron grandes ventajas para la construcción de vivienda para población de ingresos medios y altos en la "Ciudad central": ellos construyeron la mayor parte de las 33,497 viviendas producidas en el período ${ }^{16}$. Las estadísticas oficiales muestran algunos de los efectos de esta política:

- En las cuatro Delegaciones que integran la "Ciudad central" la pérdida de población se aminoró entre 2000 y 2005 y se revirtió entre 2005 y 2010; mientras que la vivienda se incrementó en toda esa década.

- Paradójicamente, las ocho Delegaciones que presentan suelo de conservación ecológico, tuvieron en la última década un incremento poblacional de 339,912 habitantes y 206,238 viviendas. Además, tenemos varias evidencias que indican que la mancha urbana continúa creciendo sobre suelo de conservación ecológico en el DF, a través de asentamientos humanos irregulares.

El Bando 2 triplicó los precios del suelo en las cuatro Delegaciones centrales y otras partes de la ciu$\mathrm{dad}^{17}$. En este contexto, selectos barrios del sur y del poniente se pusieron de moda o reforzaron su reputación entre la población joven y han sido el objetivo de desarrolladores inmobiliarios para la

16 Secretaría de Desarrollo Urbano y Vivienda, 2006.

17 Delgadillo, 2014. construcción de lofts, pequeños departamentos, galerías de arte, bares y restaurantes (Roma, Condesa, Hipódromo, Polanco, Juárez).

El encarecimiento de estas áreas urbanas dificulta cada vez más la permanencia de la población de bajos ingresos. Este hecho es reconocido por autoridades, especialistas del desarrollo urbano y los medios de comunicación. Por ejemplo:

- Laura Gómez señalaba que las "rentas caras expulsaron a 1.7 millones de personas a la periferia en 30 años"18.

- La Cámara Nacional de la Industria de Desarrollo y Promoción de Vivienda decía que la Ciudad de México se había convertido en una ciudad elitista, donde sólo se construía vivienda para altos estratos socioeconómicos. Por ello, la Cámara pedía modificar las normas urbanas para densificar al máximo la ciudad y (supuestamente) abaratar los costos de la vivienda ${ }^{19}$.

En este contexto, aumenta la emigración de la población oriunda del DF al Estado de México, donde el suelo y la vivienda son más baratos: el INEGI registró que entre 2005 y 2010 un total de 127 mil personas originarias del DF desplazaron su residencia al vecino Estado de México para

\footnotetext{
18 Gómez, 2015.

19 Cruz, 2015.
} 
TABLA 2. POLÍTICAS DE DESARROLLO URBANO INTENSIVO 2000 - 2016

\begin{tabular}{|c|c|c|c|}
\hline Gobierno & $2000-2006$ & 2007-2012 & 2012-2018 \\
\hline Política & Bando 2. & $\begin{array}{l}\text { Desarrollo urbano competitivo, equi- } \\
\text { tativo y sustentable. }\end{array}$ & $\begin{array}{l}\text { Ciudad compacta, dinámica, } \\
\text { policéntrica y equitativa. }\end{array}$ \\
\hline $\begin{array}{l}\text { Eje } \\
\text { conductor }\end{array}$ & $\begin{array}{l}\text { Política habitacional. } \\
\text { Corredores turísticos. }\end{array}$ & $\begin{array}{l}\text { Desarrollos inmobiliarios privados. } \\
\text { (Re)creación de espacio público y } \\
\text { construcción de vivienda. }\end{array}$ & $\begin{array}{l}\text { Desarrollos inmobiliarios } \\
\text { privados. } \\
\text { Zonas de Desarrollo Económi- } \\
\text { co y Social (ZODES). }\end{array}$ \\
\hline Objetivos & $\begin{array}{l}\text { Repoblar la "Ciudad central" } \\
\text { y evitar la expansión anárqui- } \\
\text { ca de la mancha urbana. }\end{array}$ & $\begin{array}{l}\text { Redensificar toda la ciudad y de- } \\
\text { tener el crecimiento de la mancha } \\
\text { urbana. }\end{array}$ & $\begin{array}{l}\text { Redensificar, intensificar, reci- } \\
\text { clar y verticalizar la ciudad; } y \\
\text { proteger el medio ambiente. }\end{array}$ \\
\hline Estrategias & $\begin{array}{l}\text { Construcción de conjuntos } \\
\text { habitacionales. Mejoramiento } \\
\text { y ampliación de vivienda. } \\
\text { Incentivos fiscales y } \\
\text { administrativos. }\end{array}$ & $\begin{array}{l}\text { Fomento del uso intensivo del suelo } \\
\text { en zonas que cuentan con infraes- } \\
\text { tructuras y servicios suficientes. } \\
\text { Aumentar los coeficientes de ocupa- } \\
\text { ción y utilización del suelo. }\end{array}$ & $\begin{array}{l}\text { Densificación en áreas con } \\
\text { potencial de reciclamiento. } \\
\text { Intensificación y diversifica- } \\
\text { ción de usos del suelo en con- } \\
\text { diciones de "sustentabilidad" y } \\
\text { rentabilidad. }\end{array}$ \\
\hline Programas & $\begin{array}{l}\text { Vivienda en conjunto en } \\
\text { las cuatro Delegaciones } \\
\text { Centrales. } \\
\text { Meioramiento habitacional en }\end{array}$ & \multicolumn{2}{|c|}{$\begin{array}{l}\text { Vivienda en conjunto en toda la ciudad. } \\
\text { Mejoramiento habitacional en el suelo urbano del DF. } \\
\text { Programa Comunitario de Mejoramiento Barrial. }\end{array}$} \\
\hline & $\begin{array}{l}\text { Mejoramiento habitacional en } \\
\text { todo el suelo urbano del DF. }\end{array}$ & $\begin{array}{l}\text { Programa de recuperación del Espa- } \\
\text { cio Público. } \\
\text { Introducción del programa EcoBici }\end{array}$ & $\begin{array}{l}\text { Programa de recuperación del } \\
\text { Espacio Público y Parques de } \\
\text { bolsillo. } \\
\text { Ampliación del programa } \\
\text { EcoBici }\end{array}$ \\
\hline
\end{tabular}

Fuente: Elaboración propia. 
incrementar el número de 255,000 a 382,200 personas $^{20}$. La autoridad local en materia de desarrollo urbano y vivienda, asegura que cada año cien mil personas son desplazadas de la capital mexicana por los altos costos del suelo ${ }^{21}$.

\section{Nuevas formas de gestión urbana}

En el contexto de estas políticas urbanas promotoras de la inversión privada, se han creado nuevas figuras de gestión urbana, a través de asociaciones público privadas, que emulan la figura del City Manager de algunas ciudades estadounidenses y algunos programas de urbanización europeos: el Estado aporta el suelo y la infraestructura, y los privados las inversiones.

El antecedente de estas formas de asociación público privadas lo constituye la agencia inmobiliaria y de servicios del GDF: Servicios Metropolitanos Sociedad Anónima de Capital Variable, creada en 1977 con el objeto de administrar propiedades desincorporadas del gobierno local, y de planear, construir, comercializar, concesionar y operar estacionamientos, unidades habitacionales, equipamiento de cultura y entretenimiento, y medios publicitarios. Esta fue la entidad responsable de la

20 Instituto Nacional de Estadística, Geografía e Informática, 2011. 21 Llanos y Gómez, 2013 urbanización de Santa Fe, el mega centro global de negocios, comercios, servicios y residencia de la ciudad.

Otro antecedente se remonta al primer gobierno democrático de la Ciudad de México (1997-2000), en la construcción de los puentes para dar accesibilidad vial a Santa Fe. Esta obra se realizó a través de un Sistema de Actuación por Cooperación: el sector privado financió la obra y el gobierno local en permuta otorgó un terreno en Santa Fe de 38.7 hectáreas ${ }^{22}$. La permuta fue calificada como un "negociazo" porque esa vialidad revalorizó el predio recibido a cambio de construir los puentes $^{23}$. Es decir, se permitió la urbanización de tres barrancas de suelo de conservación ecológico, para la construcción de un puente que al gobierno "no le costó nada".

En 2007 se creó la Agencia de Promoción, Inversión y Desarrollo para la Ciudad de México, PROCDMX. Se trata de una paraestatal con capital público y formas de funcionamiento privado que promueve la realización de obras y servicios urbanos, a través de asociaciones público privadas. Entre los principales (mega)proyectos de esta Agencia están: los Centros de Transferencia Modal (de transportes) de Chapultepec y El Rosario, el Estacionamiento Plaza de la República y el malogrado Corredor Cultural de Chapultepec.

22 Secretaría de Desarrollo Urbano y Vivienda, 2006, p. 16.

23 Luna, 2004. 
En 2013 se creó la Agencia de Gestión Urbana como un órgano desconcentrado para garantizar la coordinación entre las dependencias de gobierno, paraestatales, fideicomisos, etcétera. Esta Agencia fomenta la Ciudad creativa, a través de: el Laboratorio para la Ciudad (que impulsa proyectos urbanos y revisa las mejores prácticas del mundo para adaptarlas a esta ciudad), la Maqueta de la Ciudad, (supuestamente) como apoyo para la toma de decisiones sobre los proyectos públicos y privados, y un Centro de Inteligencia Urbana que promueve una gestión urbana (pro-empresarial) eficaz y eficiente, a través del monitoreo en tiempo real de distintos indicadores urbanos.

\section{Megaproyectos urbanos}

En el contexto de éstas políticas urbanas, se han incrementado los llamados Grandes Proyectos Urbanos de promoción pública, considerados así en función de su forma de gestión público privada, además de su escala física, inversión y múltiples impactos que tiene ${ }^{24}$, que se han convertido en íconos de cada gobierno. En la tabla 3 presentamos los megaproyectos más significativos para los tres últimos gobiernos de la Ciudad de México.

Por cuestión de espacio no podemos presentar aquí los instrumentos urbanísticos, incluidos en

24 Lungo, 2004. las distintas versiones de la Ley de Desarrollo Urbano del Distrito Federal (Sistema de Actuación por Cooperación, Áreas de Gestión Estratégica, Sistema de Transferencia de Potencialidad del Desarrollo Urbano, etcétera), que han permitido la realización de varios megaproyectos.

\section{Inversiones inmobiliarias trasnacionales}

La Ciudad de México se ha convertido en una ciudad muy interesante para la inversión inmobiliaria nacional y trasnacional. De acuerdo a La Guía Inmobiliaria de México ${ }^{25}$ actualmente habría en la capital mexicana alrededor de 70 mega desarrollos inmobiliarios con más de seis millones de metros cuadrados construidos. Aquí hay edificios de corporativos trasnacionales, megaproyectos de usos mixtos o sólo residenciales, así como torres de oficinas, edificios de servicios y centros comerciales.

- Entre los inversionistas más importantes destacaban: Carso en el "Nuevo Polanco", Mexico Retail Properties, Fibra Uno, Abilia, IdeUrban, Artha Capital, DANHOS, E-Group, ICA, Reichmann y Sordo Madaleno.

- Entre los megaproyectos físicamente más grandes estaban: "Nuevo Polanco" (Ciudad Slim),

25 Real Estate Market \& Lifestyle, 2014 y 2015. 


\section{TABLA 3. PRINCIPALES MEGAPROYECTOS URBANOS PÚBLICOS 2000 - 2016}

\section{$2000-2006$}

Programa de rescate de (una parte de) el Centro Histórico.

\section{7-2012}

Programa de recuperación del Centro Histórico, ampliación a Garibaldi (Norte) y La Merced (Oriente).

\section{$2012-2018$}

Programa de rescate del Centro Histórico.

Programa de Rescate Integral de La Merced.

Remozamiento del Paseo de la Reforma (Corredores turísticos).

Construcción de los puentes de Los Poetas, para la accesibilidad de Santa Fe.

Construcción de Distribuidores viales y Vialidades en segundos pisos públicos.

Metrobus línea 1.

Proyecto de Ferrocarril suburbano. obsoleta para el "Nuevo Polanco"
Construcción de la Súper-vía del Poniente para la accesibilidad de Santa Fe (vialidad de peaje)*

Construcción de vialidades en segundos pisos de peaje*.

\section{Metrobus líneas 2 y 4.}

Metrobus líneas 5 y 6.

Construcción del Ferrocarril suburbano.

Construcción de la línea 12 del STC

Metro.

Construcción de la Plaza Mariana, megaproyecto de la iglesia católica financiado por Carlos Slim.

Construcción de la Arena México.

Construcción de Mitikah Ciudad Progresiva.

Construcción del "Nuevo Polanco" y de alrededor de 20 megaproyectos.

\section{Cierre y reparación de la línea 12 de STC Metro.}

ZODES: Ciudad de la Salud, Ciudad Administrativa, Ciudad del Futuro, Corredor cultural, etcétera.

\section{Continuación de Mitikah Ciudad} Progresiva.

Construcción del "Nuevo Polanco" y de alrededor de 70 megaproyectos.

* Construcción de 52 Kilómetros de vialidades de peaje que por 30 años se concesionaron a: Obrascón Huarte Lain (OHL) empresa española envuelta en escándalos de corrupción por diversas obras en el Estado de México; Ingenieros Civiles y Asociados y dos empresas del Ing. Slim (Inbursa y Carso); y Cementos Mexicanos (CEMEX), sección hasta ahora no construida. Por su parte, la Súper-vía Poniente se otorgó a Copri y $\mathrm{OHL}^{1}$.

Fuente: Elaboración propia 
Picacho LifeStyle Center, Vía Vallejo, Espacio Condesa, Mitikah Ciudad Progresiva y Torre Diana.

Los capitales fundamentalmente son mexicanos, estadounidenses y españoles, pero también hay paquetes de inversiones con capitales de muchos otros países. Estas inversiones han sido favorecidas y promovidas a partir de reformas a la Ley del Impuesto sobre la Renta, realizadas en 2011, que crean la figura de Fideicomisos de Inversión y Bienes Raíces (FIBRAS) para la adquisición y construcción de inmuebles para venta o arrendamiento. Los FIBRAS tienen facilidades fiscales y administrativas para integrar inversiones diversas (pequeñas y grandes, locales o extranjeras) en la realización de proyectos de gran escala y para colocar Certificados Bursátiles Inmobiliarios en la Bolsa de Valores. Aquí, las rentas fijas se obtienen de la venta o alquiler de los inmuebles incluidos en los portafolios de inversiones inmobiliarias, y las rentas variables dependen de la apreciación de los certificados de los inmuebles en la Bolsa de Valores. Se trata de sofisticados instrumentos de la financiarización trasnacional que de facto entregan el desarrollo urbano a los flujos de capital trasnacional en operaciones de gran escala.

\section{Las Zonas de Desarrollo Económico y Social (ZODES)}

Las ZODES, impulsadas por el gobierno local actual en algunas colonias centrales, populares y de clase media, promueven una ciudad compacta y densa, que atraiga a nuevos pobladores y revitalice áreas urbanas decretadas "obsoletas y deterioradas". Se trata de especializar zonas que ya cuentan con una cierta especificidad funcional, acompañándolas de viviendas y servicios "modernos". Más allá de las buenas intenciones que dicen generar empleos y beneficios sociales, se privilegia el negocio privado.

- La Ciudad de la Salud se realiza en torno a un "cluster" de hospitales públicos de especialidades y un conjunto hospitalario privado. Aquí, bajo el discurso de fortalecer el turismo de salud, el proyecto prácticamente consiste en la ampliación del centro privado Medica Sur y el impulso a la densificación urbana en zonas donde la norma urbana no permitía más de tres niveles de construcción.

- La Ciudad Administrativa, en la popular colonia Doctores pretende crear departamentos en torres, oficinas y centros culturales. Se trata de ampliar la oferta inmobiliaria de la vecina colonia Roma. 
- El Corredor Cultural Chapultepec, en las inmediaciones de los barrios Roma, Condesa y Juárez, pretendía construir un parque lineal elevado con biblioteca digital, huertos urbanos, estacionamientos subterráneos, comercios y servicios, que se concesionarían a la empresa privada INVEX por 40 años (95\% de las rentas urbanas son para ellos y 5\% para el gobierno local). PROCDMX señalaba que, para confrontar los problemas de la Avenida Chapultepec y las colonias adyacentes, era imprescindible la creación de este "espacio público" que favorecería a peatones y ciclistas. Sin embargo, los vecinos de esas colonias se opusieron a esa obra porque creaba un centro comercial y no resolvía, pero incrementaría los conflictos viales. El proyecto fue derogado a través de una gran movilización, que ganó una consulta pública organizada por el gobierno local en noviembre de 2015 .

- La Ciudad del Futuro o de la Innovación, en las cercanías de la Ciudad Universitaria, pretendía reciclar la planta de (producción de) asfalto con torres de departamentos, centros comerciales y de investigación. El proyecto fue derogado en enero de 2016 por el Jefe de Gobierno, debido a la oposición vecinal y a la coyuntura política en turno: la elección y designación de la Asamblea Constituyente de la Ciudad de México, encargada de redactar la constitución de la ciudad autónoma.

Muchos de estos megaproyectos públicos y privados no estaban contemplados en la planeación urbana y su construcción contraviene el marco jurídico vigente. Sin embargo, esas obras se realizan con la anuencia de un gobierno local que busca la competitividad económica, a pesar del descontento social que a menudo producen.

\section{Percepción sobre la transformación de 10 barrios}

\section{PERMANENCIA Y MOVILIDAD RESIDENCIAL}

Frente al supuesto de la gran permanencia de la población en las áreas urbanas centrales, destacamos que una gran cantidad de los 3,000 encuestados son nuevos residentes de la vivienda y el barrio en donde fueron encuestados:

- Más de la mitad de los encuestados (54.6\%) no vivían en el mismo barrio antes de ocupar la vivienda actual. En Xoco, Alameda Sur y San Álvaro este porcentaje es de más del 60\%.

- Un $43.7 \%$ de los encuestados no vivía en la misma Delegación antes de ocupar la vivienda actual. En Xoco, Concepción-Del Carmen y Alameda Sur el porcentaje es mayor del 50\%.

revista invi 31(88) : 101-129, noviembre de 2016119 
- Un $11.9 \%$ de los encuestados no vivía en el DF antes de ocupar la vivienda actual. El porcentaje se incrementa casi a la quinta parte de los encuestados en Alameda Sur (18.2\%) y La Merced (17.4\%).

En relación a la vivienda ocupada, el 31.3\% de los encuestados llegó a vivir a la vivienda actual diez años atrás y el 41.9\% quince años atrás ${ }^{26}$. De ellos:

- $01.8 \%$ tiene menos de un año (destaca La Vieja Merced y la Roma-Condesa).

- $14.8 \%$ de 1 a 5 años (destaca la Roma-Condesa y Nueva Granada).

- $14.7 \%$ tiene viviendo de 6 a 10 años (destacan Alameda Sur y Guerrero-Los Ángeles).

- $10.6 \%$ tiene viviendo de 11 a 15 años (destaca Alameda Sur y Guerrero-Los Ángeles).

Hay barrios en donde alrededor del 50\% de la población encuestada llegó a vivir a la vivienda en los últimos 15 años (Alameda Sur, Guerrero-Los Ángeles y Polanco). En sentido contrario, destacan los encuestados que tienen más de 20 años de residencia, que sumados a los que siempre han vivido en la misma vivienda alcanzan el $70.3 \%$ en
Concepción-Del Carmen, 57\% en San Álvaro y $52.5 \%$ en Doctores.

Conviene añadir, que un $12.2 \%$ de los entrevistados sí se quisieran cambiar de casa (una cuarta parte en la Doctores y La Merced), frente a una amplia mayoría (85.7\%) que no le interesa mudarse de casa y de barrio.

\section{LA TRANSFORMACIÓN DEL BARRIO}

De acuerdo a la percepción de los encuestados (tabla 5), los barrios que más se transforman (con relación al incremento de bares, locales comerciales, oficinas, vivienda nueva y vivienda en renta) son Roma-Condesa, Nueva Granada, Polanco y Xoco. En cambio, los barrios que menos se transforman son la Vieja Merced y Alameda Sur (figuras 4 y 5).

Curiosamente los vecinos de Coyoacán-Del Carmen son quienes más perciben negativamente la construcción de viviendas.

26 Este dato es interesante, pues a partir de 2000 iniciaron las políticas de desarrollo urbano intensivo. 


\section{TABLA 4. AÑOS DE VIVIR EN LA VIVIENDA (PORCENTAJES)}

\begin{tabular}{|c|c|c|c|c|c|c|c|c|c|c|c|}
\hline 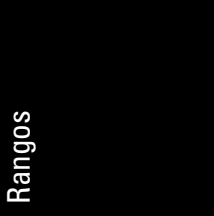 & 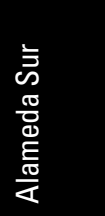 & 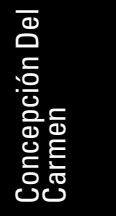 & $\begin{array}{l}\mathscr{Z} \\
\text { 음 } \\
\text { 음 }\end{array}$ & 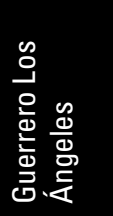 & 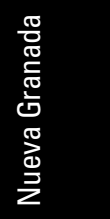 & $\begin{array}{l}\text { 음 } \\
\text { 등 } \\
\frac{0}{0}\end{array}$ & 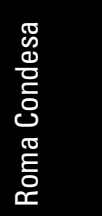 & 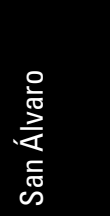 & 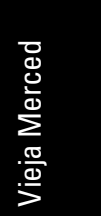 & : & $\begin{array}{l}\bar{\pi} \\
\text { 음 }\end{array}$ \\
\hline $\begin{array}{l}\text { Menos de un } \\
\text { año }\end{array}$ & 0.7 & 1.0 & 2.0 & 0.3 & 1.3 & 2.3 & 3.3 & 2.0 & 4.3 & 0.3 & 1.8 \\
\hline $1-5$ años & 12.7 & 8.0 & 11.3 & 16.1 & 20.4 & 17.0 & 21.1 & 9.0 & 14.4 & 18.0 & 14.8 \\
\hline $6-10$ años & 20.1 & 6.0 & 14.6 & 19.7 & 14.7 & 17.3 & 11.4 & 14.7 & 13.4 & 15.3 & 14.7 \\
\hline $11-15$ años & 15.7 & 6.3 & 13.3 & 15.1 & 9.0 & 11.7 & 6.4 & 7.0 & 12.0 & 9.7 & 10.6 \\
\hline $16-20$ años & 6.4 & 7.0 & 4.0 & 6.0 & 5.7 & 10.3 & 9.0 & 8.3 & 7.7 & 11.0 & 7.5 \\
\hline Más de 20 años & 20.4 & 30.3 & 22.6 & 28.8 & 16.1 & 18.7 & 23.4 & 30.0 & 21.1 & 29.7 & 24.1 \\
\hline $\begin{array}{l}\text { Siempre he } \\
\text { vivido aquí }\end{array}$ & 19.4 & 40.0 & 29.9 & 11.4 & 31.4 & 21.0 & 24.7 & 27.0 & 21.4 & 10.3 & 23.7 \\
\hline No contestó & 4.7 & 1.3 & 2.3 & 2.7 & 1.3 & 1.7 & 0.7 & 2.0 & 5.7 & 5.7 & 2.8 \\
\hline Total & 100.0 & 100.0 & 100.0 & $100.0 \%$ & 100.0 & 100.0 & 100.0 & 100.0 & 100.0 & 100.0 & 100.0 \\
\hline
\end{tabular}

Fuente: Elaboración propia con base en la Encuesta Hábitat y Centralidad, 2015. 


\section{TABLA 5. LA TRANSFORMACIÓN PERCIBIDA DEL BARRIO}

\begin{tabular}{|c|c|c|c|c|c|c|c|c|c|c|c|}
\hline 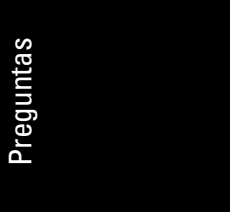 & 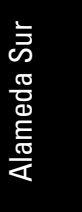 & 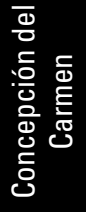 & 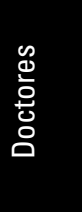 & 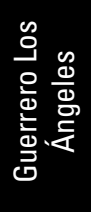 & 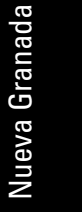 & 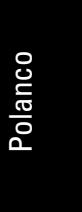 & 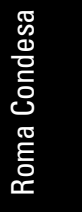 & 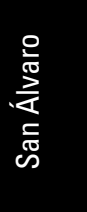 & 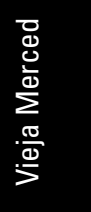 & $\begin{array}{l}0 \\
0 \\
0\end{array}$ & $\begin{array}{l}\bar{\pi} \\
\text { 으 }\end{array}$ \\
\hline $\begin{array}{l}\text { Incremento de } \\
\text { bares* }^{*}\end{array}$ & 32.00 & 23.00 & 7.60 & 31.30 & 12.70 & 24.60 & 69.00 & 3.70 & 13.60 & 2.00 & 21.90 \\
\hline $\begin{array}{l}\text { Incremento } \\
\text { de locales } \\
\text { comerciales* }\end{array}$ & 34.90 & 28.10 & 36.70 & 32.30 & 64.90 & 53.30 & 66.60 & 8.60 & 34.80 & 32.30 & 39.20 \\
\hline $\begin{array}{l}\text { Incremento de } \\
\text { oficinas* }\end{array}$ & 32.20 & 31.00 & 21.90 & 19.30 & 73.00 & 67.90 & 71.70 & 4.00 & 13.40 & 48.80 & 38.30 \\
\hline $\begin{array}{l}\text { Incremento de } \\
\text { vivienda nueva* }\end{array}$ & 11.70 & 11.70 & 58.50 & 47.40 & 79.60 & 48.70 & 79.30 & 54.50 & 17.30 & 72.00 & 48.10 \\
\hline $\begin{array}{l}\text { Incremento de } \\
\text { vivienda en renta* }\end{array}$ & 17.00 & 20.00 & 30.00 & 48.40 & 71.00 & 65.10 & 76.20 & 41.00 & 31.40 & 64.30 & 46.40 \\
\hline $\begin{array}{l}\text { Encarecimiento de } \\
\text { rentas }^{*}\end{array}$ & 55.90 & 72.30 & 43.00 & 38.60 & 73.80 & 79.00 & 89.60 & 70.30 & 69.90 & 75.50 & 66.60 \\
\hline $\begin{array}{l}\text { Incremento del va- } \\
\text { lor de la vivienda* }\end{array}$ & 67.70 & 76.50 & 64.30 & 64.10 & 80.00 & 82.00 & 81.90 & 71.70 & 70.00 & 86.40 & 74.40 \\
\hline $\begin{array}{l}\text { Efecto negativo de } \\
\text { la construcción de } \\
\text { vivienda }\end{array}$ & 41.70 & 90.70 & 51.30 & 62.70 & 66.70 & 58.30 & 72.20 & 86.70 & 59.90 & 74.60 & 66.50 \\
\hline
\end{tabular}


FIGURA 4. COYOACÁN. PROTESTA VECINAL CONTRA EL INCREMENTO DE BARES.

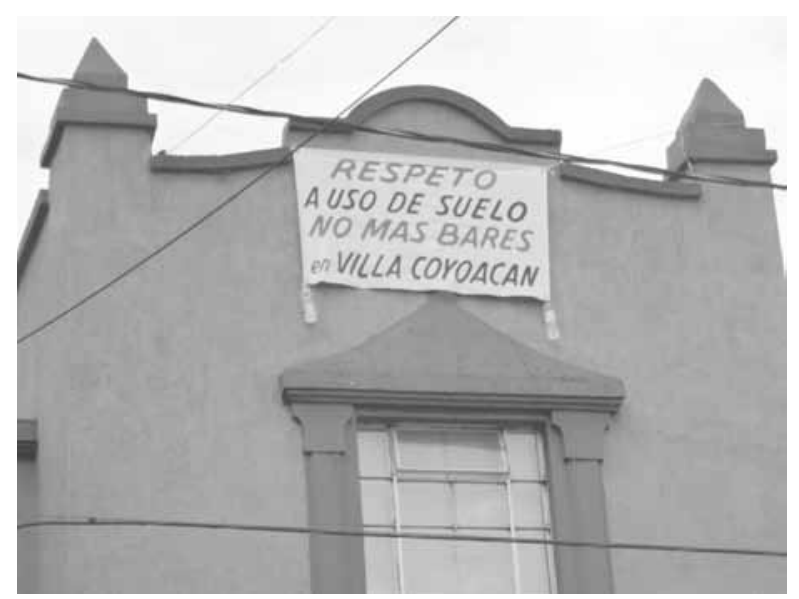

Foto: Autor
FIGURA 5. ALAMEDA SUR. ANUNCIO DE NUEVOS DEPARTAMENTOS.

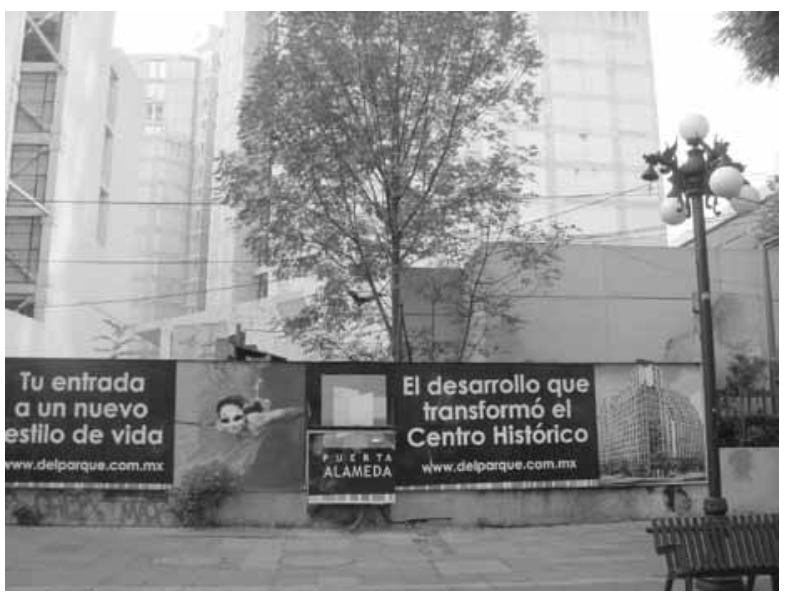

Foto: Autor

\section{¿VECINOS GENTRIFICADORES?}

En todas las colonias o barrios, con excepción de Concepción-Del Carmen, los encuestados han visto llegar a nuevos vecinos. Los mayores porcentajes se presentan en Xoco (74\%), Roma-Condesa
(70.3\%), Polanco (68.7\%), Doctores (66.3\%), Nueva Granada (64.7\%) y Guerrero-Los Ángeles (61.3\%). ¿Quiénes son estos nuevos vecinos de acuerdo a las percepciones de los residentes entrevistados? 
TABLA 6. PERCEPCIONES SOBRE LOS NUEVOS RESIDENTES Y LA DESAPARICIÓN DEL PEQUEÑO COMERCIO

\begin{tabular}{|c|c|c|c|c|c|c|c|c|c|c|c|}
\hline Preguntas & $\begin{array}{l}\text { Alam- } \\
\text { eda Sur }\end{array}$ & $\begin{array}{l}\text { Concep- } \\
\text { ción del } \\
\text { Carmen }\end{array}$ & $\begin{array}{l}\text { Docto- } \\
\text { res }\end{array}$ & $\begin{array}{l}\text { Guerrero } \\
\text { Los Ánge- } \\
\text { les }\end{array}$ & $\begin{array}{l}\text { Nueva } \\
\text { Grana- } \\
\text { da }\end{array}$ & $\begin{array}{l}\text { Po- } \\
\text { lanco }\end{array}$ & $\begin{array}{l}\text { Roma } \\
\text { Conde- } \\
\text { sa }\end{array}$ & $\begin{array}{l}\text { San } \\
\text { Álvaro }\end{array}$ & $\begin{array}{l}\text { Vieja } \\
\text { Mer- } \\
\text { ced }\end{array}$ & Xoco & Total \\
\hline $\begin{array}{l}\text { Llegada de nuevos } \\
\text { vecinos }\end{array}$ & 51.20 & 34.30 & 66.30 & 61.30 & 64.70 & 68.70 & 70.30 & 54.70 & 56.30 & 74.00 & 60.20 \\
\hline $\begin{array}{l}\text { Sítienen más in- } \\
\text { gresos }\end{array}$ & 6.50 & 16.50 & 29.60 & 9.80 & 46.10 & 38.30 & 38.40 & 27.40 & 14.20 & 66.20 & 31.50 \\
\hline Sí son más jóvenes & 31.20 & 75.70 & 58.30 & 71.20 & 59.60 & 58.00 & 69.20 & 74.40 & 23.70 & 71.50 & 59.50 \\
\hline $\begin{array}{l}\text { Sí tienen actitudes } \\
\text { diferentes }\end{array}$ & 5.20 & 7.80 & 33.70 & 14.70 & 33.20 & 29.50 & 37.90 & 20.10 & 6.50 & 10.40 & 21.20 \\
\hline $\begin{array}{l}\text { Sí desaparece el } \\
\text { pequeño comercio }\end{array}$ & 46.00 & 26.00 & 40.80 & 24.30 & 52.00 & 55.30 & 48.70 & 15.30 & 43.50 & 72.70 & 42.50 \\
\hline
\end{tabular}

Fuente: Elaboración propia con base en Encuesta Hábitat y Centralidad, 2014.

En cuatro barrios se presentan los porcentajes más altos en las percepciones sobre el tipo de nuevos residentes con mayores ingresos, más jóvenes y actitudes diferentes: Xoco, Roma-Condesa, Nueva Granada y Polanco. Sin embargo, también destacamos que en Guerrero-Los Ángeles y Doctores (donde se ha construido vivienda social) se percibe que hay nuevos residentes más jóvenes y con actitudes diferentes. No hay espacio aquí sino para mencionar de manera general las respuestas abiertas que los encuestados dieron sobre las "actitudes diferentes" de los nuevos residentes, que agrupamos en tres rubros:
- Diferencias culturales: tienen otra religión, hablan otros idiomas, otras formas de hablar, son gays, consumen drogas, hacen fiestas.

- Convivencia social positiva: son limpios, pasean sus perros y limpian sus excrementos, saludan.

- Convivencia social negativa: son escandalosos, prepotentes, son "más payasos".

Sobre la desaparición del pequeño comercio de proximidad en el barrio (resultados agregados en la tabla 6), destaca la percepción de un alto 
porcentaje de encuestados en Xoco (72.7\%), Polanco (55.3\%) y Nueva Granada (52\%).

En síntesis, podemos afirmar que los barrios que más se transforman en dirección a procesos de gentrificación, de acuerdo a nuestras encuestas, son:

- Xoco, que padece una gran transformación debido a la construcción de Mitikah Ciudad Progresiva, en el extremo norte, y las City Towers al sur del barrio (figura 6).

- Roma-Condesa y Polanco, que padecen los embates de inversionistas que han encontrado en la construcción de departamentos de lujo tipo loft (nuevos y en edificios rehabilitados) y en la apertura de bares y restaurantes un negocio lucrativo, que genera malestar en la población residente (figura 7).

- La ex área fabril de la Nueva Granada (conocida como Nuevo Polanco), donde la transformación de la zona es acelerada y en gran escala. Cada vez se edifican más torres de viviendas, servicios y comercios frente a los antiguos barrios obreros (figura 8).
FIGURA 6. XOCO. CITY TOWERS.

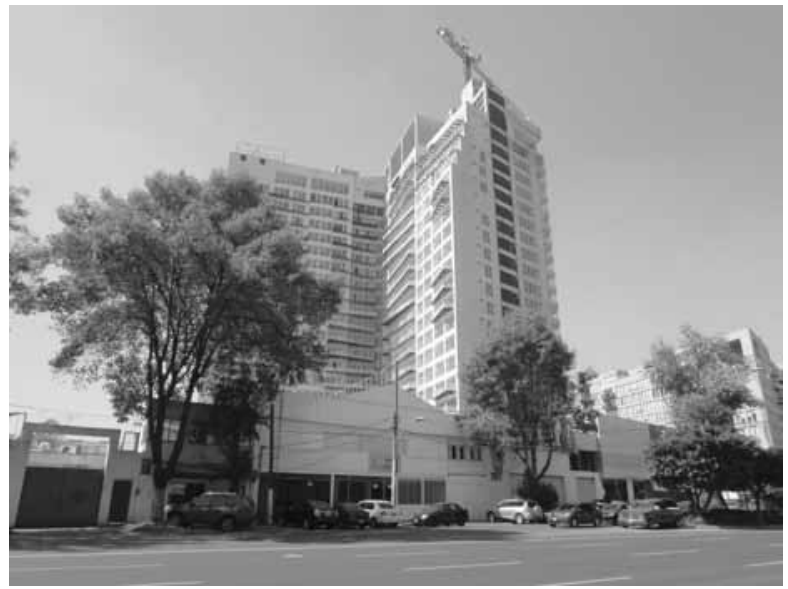

Foto: Autor

\section{FIGURA 7. CONDESA. AL FONDO, DENSIFICACIÓN EN TORNO A VIALIDADES PRIMARIAS.}

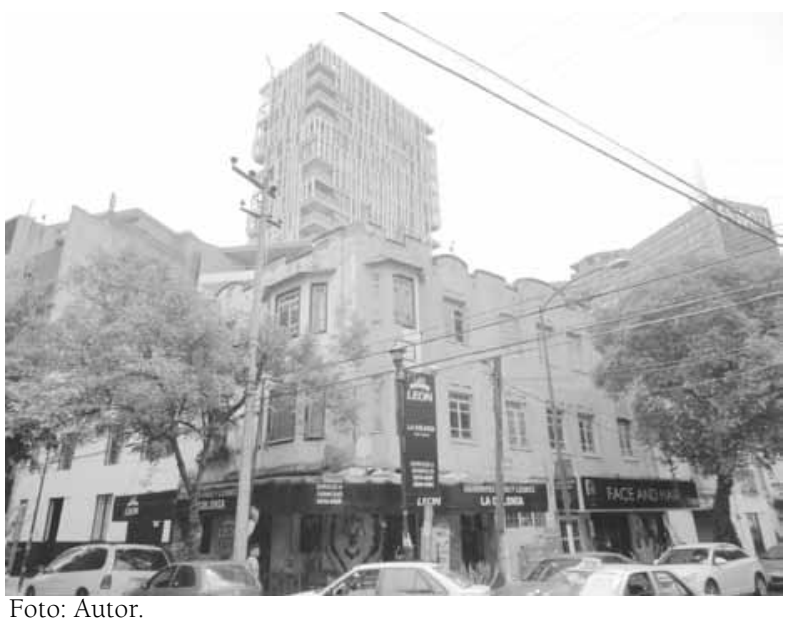




\section{FIGURA 8. NUEVA GRANADA. EDIFICIOS POLÁREA EN "NUEVO POLANCO".}

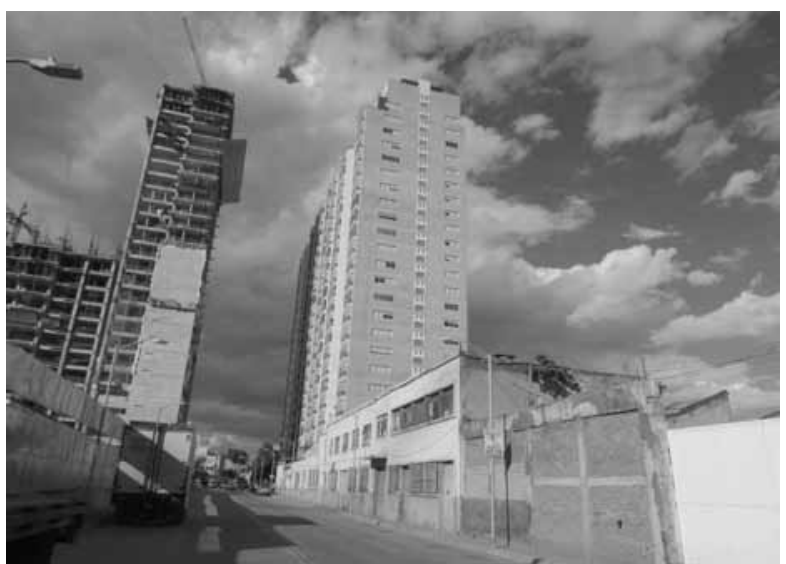

Foto: Autor.

A manera de hipótesis sostenemos que en la Vieja Merced y en la colonia Doctores los cambios se perciben menos que en otros barrios, porque los megaproyectos anunciados por la actual administración aún no se llevan a cabo, al menos en la escala anunciada. En el caso de La Alameda Sur es curioso que los encuestados que habitan el centro y el sur de ese polígono parecen no percibir los fuertes cambios de las manzanas que colindan con el parque Alameda, donde el hombre más rico de México y otros inversionistas han continuado invirtiendo en esa zona (Hotel 5 estrellas, centro de convenciones, lofts, plazas comerciales, etcétera).

\section{Conclusiones}

Las políticas públicas de desarrollo urbano intensivo tienen un discurso noble y aceptable, pues se proponen evitar la expansión urbana que destruye el suelo verde e incrementa los traslados de la población y el uso del transporte; y crear los atributos positivos de la ciudad compacta: mezcla de funciones urbanas, usos del suelo y estratos socioeconómicos. Sin embargo, éstas políticas de crecimiento sobre la ciudad existente, no son universales, ni democráticas, ni accesibles para todos, ni son neutras, ni están despolitizadas. En efecto, estas políticas en la Ciudad de México:

- Promueven la particular revalorización de selectos territorios centrales.

- Elevan los precios del suelo y de la vivienda.

- Construyen torres de departamentos y crean comercios y una oferta gastronómica y de entretenimiento, cuyos precios son inaccesibles para la mayoría de la población residente de esos barrios y de esta ciudad.

- Promueven un tipo de inversión privada lucrativa que el gobierno local la legitima como si se tratara de una acción filantrópica: el sector privado hace obras que el sector público no puede hacer y al gobierno "no le cuestan nada". 
En síntesis, éstas políticas han contribuido a la creación de una ciudad cada vez más cara, exclusiva y excluyente, particularmente en ciertos barrios y colonias atractivos y rentables para la inversión privada. Así, la ciudad compacta por los precios del suelo y la vivienda es un lujo que pocos pueden pagar.

Las ininterrumpidas políticas de desarrollo urbano centrifugo llaman la atención por dos causas adicionales: uno es la relativa continuidad en las políticas públicas, a pesar de los cambios de gobierno; la otra, es que estas políticas públicas se presentan como de "izquierda", cuando abiertamente favorecen los negocios privados, el lucro y la ciudad es concebida como una máquina que produce ganancias. Las nuevas formas de gestión urbana y la creación de agencias de desarrollo urbano son un elocuente ejemplo del urbanismo pro empresarial. Desconocemos si los gobiernos de "izquierda" asumen por gusto o necesidad la financiarización del capitalismo en su fase actual, con los enormes flujos de capitales trasnacionales que se invierten en los negocios inmobiliarios y "detonan" la economía local. Ziccardi y Álvarez ${ }^{27}$ sugieren que el GDF "ha tenido" que atraer distintas inversiones locales y extranjeras, a través de instrumentos de asociación público-privados, porque el gobierno federal ha reducido las participaciones federales.
En esta versión, el GDF ejerce un tipo de política neoliberal por culpa del gobierno federal.

Por otra parte, los resultados de las 3,000 encuestas aplicadas en diez barrios centrales indican que sólo selectos barrios centrales han sido revalorizados y sustancialmente transformados por la acción de las políticas públicas y las inversiones privadas. La población encuestada de manera aleatoria en los diferentes barrios claramente reconoce cómo su barrio se ha modificado y percibe la llegada de nuevos residentes de mayores ingresos, más jóvenes y con actitudes diferentes a los antiguos residentes. En este sentido, podemos afirmar que la población de Xoco, Roma-Condesa, Polanco y Nueva Granada identifica claras evidencias de procesos de gentrificación, en este caso a partir del consumo de los territorios revalorizados.

Finalmente, los resultados aquí presentados de esta compleja y amplia encuesta, son provisorios y exploratorios en dos sentidos: por un lado, necesitamos hacer algunos cruces en las percepciones de la población con relación a la antigüedad de habitar el territorio y la condición de la vivienda ocupada (propia, alquiler), y, por otro lado, nos proponemos realizar futuras encuestas en las mismas "áreas testigo" para valorar las transformaciones de los barrios y en la percepción de la población en una línea de tiempo más amplia.

27 Ziccardi y Álvarez, 2015. 


\section{Bibliografía}

CRUZ, Alejandro. El DF desarrolla sólo el sector residencial; es elitista: Canadevi. [En línea]. La Jornada, 8 de mayo 2015, p. 31. Disponible en: http://www. jornada.unam.mx/2015/05/08/capital/031nlcap

DELGADILLO, Víctor. ¿Gentrificación sin desplazamiento social? Ciudades. (103): 2-8, 2014. ISSN 0187-861-1.

DELGADILLO, Víctor, coord:; DÍAZ, Ibán, coord. y SALINAS, Luis, coord. Perspectivas del estudio de la gentrificación en México y Latinoamérica. México, CONTESTED_CITIES, UNAM. 2015. 412 p. Serie Libros de investigación. ISBN 978-607-02-6971-4.

GÓMEZ, Laura. Rentas caras expulsaron a 1.7 millones de personas a la periferia en 30 años: Lobo. [En línea]. La Jornada, 16 de abril 2015, p. 32. Disponible en: http://www.jornada.unam. mx/2015/04/16/capital/032n2cap

HIERNAUX Daniel y GONZÁLEZ Imelda. Turismo y gentrificación, pistas teóricas de una articulación. Revista de Geografía Norte Grande. (58): 55-70, 2014. ISSN 0718-3402. DOI 10.4067/ S0718-34022014000200004.

INSTITUTO Nacional de Estadística, Geografía e Informática. Panorama sociodemográfico del Distrito Federal. México, INEGI. 2011. 50 p. ISBN 978-607-494-205-7.

JEFATURA de Gobierno. Acuerdo por el que se expiden las políticas de desarrollo urbano y ordenamiento territorial sustentable en materia de desarrollo social, ambiental y económico de la Ciudad de México. Gaceta Oficial del Distrito Federal. (1528): 3-5, 2013.

LEES, Loretta; SLATER, Tom y WYLY, Elvin. Gentrification. New York, Taylor \& Francis. 2008. 344 p. ISBN 978-0-415-95036-7.

LLANOS, Raúl y GÓMEZ, Laura. Por el alto costo del suelo, 100 mil personas al año dejan el DF: Seduvi. [En línea]. La Jornada, 01 de octubre 2013, p. 34. Disponible en: http://www.jornada.unam. mx/2013/10/01/capital/034nlcap

LÓPEZ MORALES, Ernesto. Gentrificación en Chile: aportes conceptuales y evidencias para una necesaria. Revista de Geografía Norte Grande. (56): 31-52, 2013. ISSN 0718-3402. DOI 10.4067/ S0718-34022013000300003.

LUNA, Jorge de. Negociazo: entregan puentes a medias, pero ganarán 350 MDP. [En línea]. La Crónica, 18 de octubre 2004. Disponible en: http:// www.cronica.com.mx/notas/2004/148904.html

LUNG0, Mario, comp. Grandes proyectos urbanos. El Salvador, UCA Editores. 2004. 245 p. ISBN 9923-34-85-1.

REAL Estate Market \& Lifestyle. La guía inmobiliaria de México. (100), 2015.

REAL Estate Market \& Lifestyle. La guía inmobiliaria. (95), 2014.

QUIROZ, Héctor y CADENA, Arturo. Una reflexión sobre las formas de transformación de la ciudad a 
partir de la experiencia del taller internacional sobre gentrificación en México y Alemania. En: DELGADILLO, Víctor, coord.; DÍAZ, Ibán, coord. y SALINAS, Luis, coord. Perspectivas del estudio de la gentrificación en México y Latinoamérica. México, CONTESTED_CITIES, UNAM. 2015. p. 73-90. Serie Libros de investigación. ISBN 978-607-02-6971-4.

RODRÍGUEZ, Carla. Estado, clases y gentrificación. La política urbana como campo de disputa en tres barrios de Ciudad de Buenos Aires. En: DELGADILLO, Víctor, coord.; DÍAZ, Ibán, coord. y SALINAS, Luis, coord. Perspectivas del estudio de la gentrificación en México y Latinoamérica. México, CONTESTED_CITIES, UNAM. 2015. p. 205-227. Serie Libros de investigación. ISBN 978-607-02-6971-4.

SECRETARÍA de Desarrollo Agrario, Territorial y Urbano. Programa nacional de desarrollo urbano 2014-2018. Gaceta Oficial de la Federación. 30 de abril de 2014.

SECRETARÍA de Desarrollo Urbano y Vivienda. Agenda hacia una ciudad compacta, dinámica, policéntrica y equitativa 2013 - 2018. México, GDF-SEDUVI. 2013.28 p.

--- Sexto informe de trabajo. México, GDF - SEDUVI. 2006.

SENADO de la República; Fundación IDEA y SIMO Consulting. México compacto. Las condiciones para la densificación urbana inteligente en México. México, Grupo Impresso. 2014. 130 p.
SMITH, Neil. Towards a theory of gentrification: a back to the city movement by capital, not people. Journal of the American Planning Association. 45(4): 538548, 1979. DOI 10.1080/01944367908977002.

ZICCARDI, Alicia y ÁLVAREZ, Lucia. Políticas sociales y construcción de ciudadanía en un gobierno de izquierda: el caso de la ciudad de México. En: CARRIÓN, Fernando. El giro a la izquierda. Los gobiernos locales en América Latina. Buenos Aires, Editorial El Café de las Ciudades. 2015. p. 367-405. ISBN 978-987-3627-10-1. 